\title{
ANALISIS PERANCANGAN E-COMMERCE TART \& CAKE FAFA CHEESE BERBASIS WEB
}

\author{
Kusnandar $^{1}$, Ita Arfyanti ${ }^{2}$, Nursobah ${ }^{3}$ \\ STMIK Widya Cipta Dharma ${ }^{1,2,3}$ \\ Jl. Prof. M. Yamin No. 25, Samarinda, 75123 $3^{1,2,3}$ \\ Sur-el : kusnandar@wicida.ac.id ${ }^{1}$, ita@wicida.ac.id ${ }^{2}$, nursb@wicida.ac.id ${ }^{2}$
}

\begin{abstract}
This study discusses about e-commerce analysis and design at the Fafa Cheese shop. The sales system is still done manually, monthly data reports are still done in recording into a book which can lost sales reports, and there is no price information and tart sold, it is necessary to have the delivery status of the tart sold. The development of this sales information system uses the waterfall development system. This study aims to design an online cake sales application, provide information about prices and cakes sold and provide information that cakes have been sent to customers. The results of this study are the creation of e-commerce design, making it easier to make monthly reports, the availability of price information and cakes sold, and the statusof cake delivery if the cake has been sent to the customer.
\end{abstract}

Keywords: Analysis, Design, E-Commerce, Tart

\begin{abstract}
Abstrak : Penelitian ini membahas tentang menganalisis dan mendesain aplikasi penjualan pada toko Fafa Cheese. Sistem penjualan masih dilakukan secara manual, laporan data bulanan masih dilakukan dalam pencatatan kedalam buku yang dapat menghilangnya laporan penjualan, tidak adanya informasi harga dan kue tart yang dijual, perlu adanya status pengiriman kue tart yang dijual. Pengembangan sisteminformasi penjualan ini menggunakan metode waterfall. Penelitian ini bertujuan untukmerancang aplikasi penjualan kue secara online, memberikan informasi mengenai harga dan kue yang dijual dan memberikan informasi kue sudah dikirim ke pelanggan. Hasil dari penelitian ini adalah terciptanya rancangan aplikasi penjualan, memudahkan dalam pembuatan laporan bulanan, tersedianya informasi harga dan kue yang dijual, dan adanya status pengiriman kue jika kue sudah dikirimkan ke pelanggan.
\end{abstract}

Kata kunci: Analisis, desain, Aplikasi Penjualan, Kue Tart

\section{PENDAHULUAN}

Kue Tart adalah kue panggang berbahan dasar pastri dan diisi dengan sesuatu yang manis atau gurih, biasa lebih dikenal dengan kue ulan tahun [1]. Fafa Cheese adalah toko yang menjual berbagai jenis tart dan cake. Toko Fafa Cheese ini beralamat di Bantul, Yogyakarta. Saat ini sistem penjualan Fafa Cheese yaitu melalui media sosial seperti instagram, facebook, dan whatsapp [2],[3]. Dengan sistem penjualan yang dilakukan saat ini, pelanggan tidak mendapatkan informasi yang lebih lengkap seperti harga kue-kue yang dijual sehingga pelanggan harus menanyakan terlebih dahulu harga cake yang akan dipesan [4],[5],[6]. Adapun proses pencatatan data penjualan yang masih menggunakan buku catatan untuk menyimpan data, sehingga memungkinkan faktor non teknis seperti rusak atau hilangnya buku catatan yang ada [5],[7]. Selain itu dalam melakukan transaksi antara jual beli dengan pelanggan seperti pengiriman bukti pembayaran, pemilik toko masih menggunakan media sosial whatsapp [8],[9]. Hal ini tentunya juga memungkinkan faktor non teknis seperti data pengiriman bukti pembayaran yang terhapus, sehingga akan menghambat proses penjualan.

Berdasarkan masalah diatas, untuk membantu menyelesaikan masalah yang dihadapi maka akan dibuat suatu aplikasi penjualan cake berbasis web, 
yaitu aplikasi penjualan cake pada toko Fafa Cheese berbasis web yang diharapkan nantinya akan dapat memfasilitasi serta mengelola pencatatan penjualan pada toko Fafa Cheese. Aplikasi ini dibuat menggunakan sublime text 3 sebagai software dan MySQL server sebagai pusat database.

\section{1}

\section{METODOLOGI PENELITIAN}

Metode pengembangan sistem dalam penelitian ini adalah model air terjun (Waterfall) adalah model klasik yang bersifat sistematis, berurutan dalam membangun software [10],[11] Pada model ini dapat memungkinkan pemecahan pengembangan yang rumit menjadi beberapa langkah logis (desain, kode, pengujian, dan seterusnya) yang pada akhirnya akan menjadi produk akhir siap pakai [11].

Adapun tahapan yang terdapat dalam waterfall model adalah sebagai berikut [10]:

1. Requirements Definition, adalah proses analisis kebutuhan secara lengkap dan didefinisikan kebutuhan yang harus dipenub. oleh aplikasi yang akan dibangun. Fase ini harus dikerjakan secara lengkap untuk bisa menghasilkan desain yang lengkap.

2. System and Software Design, adalah pembuatan desain aplikasi sebelum proses coding. Desain Sistem membantu dalam menentukan perangkat keras (hardware) dan sistem persyaratan yang lain serta membantu dalam mendefinisikan arsitektur sistem secara keseluruhan.
Penelitian ini tidak belum sampai ke tahapan implementasi dan pengujian, karena hanya difokuskan pada analisis dan perancangan sistemnya.

\section{HASIL DAN PEMBAHASAN}

\subsection{Use Case Diagram Login Pengguna danAdmin}

Use case diagram login pengguna dan admin menggambarkan dimana pelanggan harus melakukan login terlebih dahulu untuk melakukan pesanan pada aplikasi toko Fafa Cheese (lihat Gambar 1), sedangkan login admin untuk dapat melakukan proses pengelolaan data pesanan dan data penjualan.

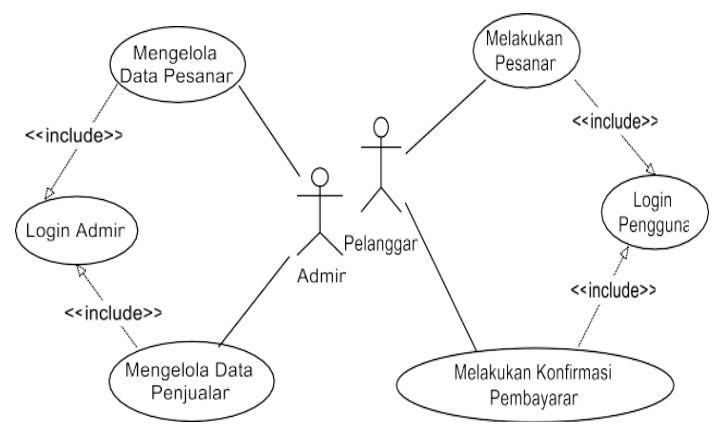

Gambar 1. Use Case Diagram login penggunadan admin

\subsection{Class Diagram}

Dapat dilihat pada gambar 2, adalah class diagram sistem pemesanan dan penjualan cake pada toko Fafa Cheese. Dalam Class diagram ini memberikan gambaran mengenai sistem atau perangkat lunak dan relasi - relasi yang ada di dalamnya. Adapun Class admin, pelanggan, type, cake, pesan, transaksi, penjualan masing - masing class ini memiliki atribut dan method tersendiri. 


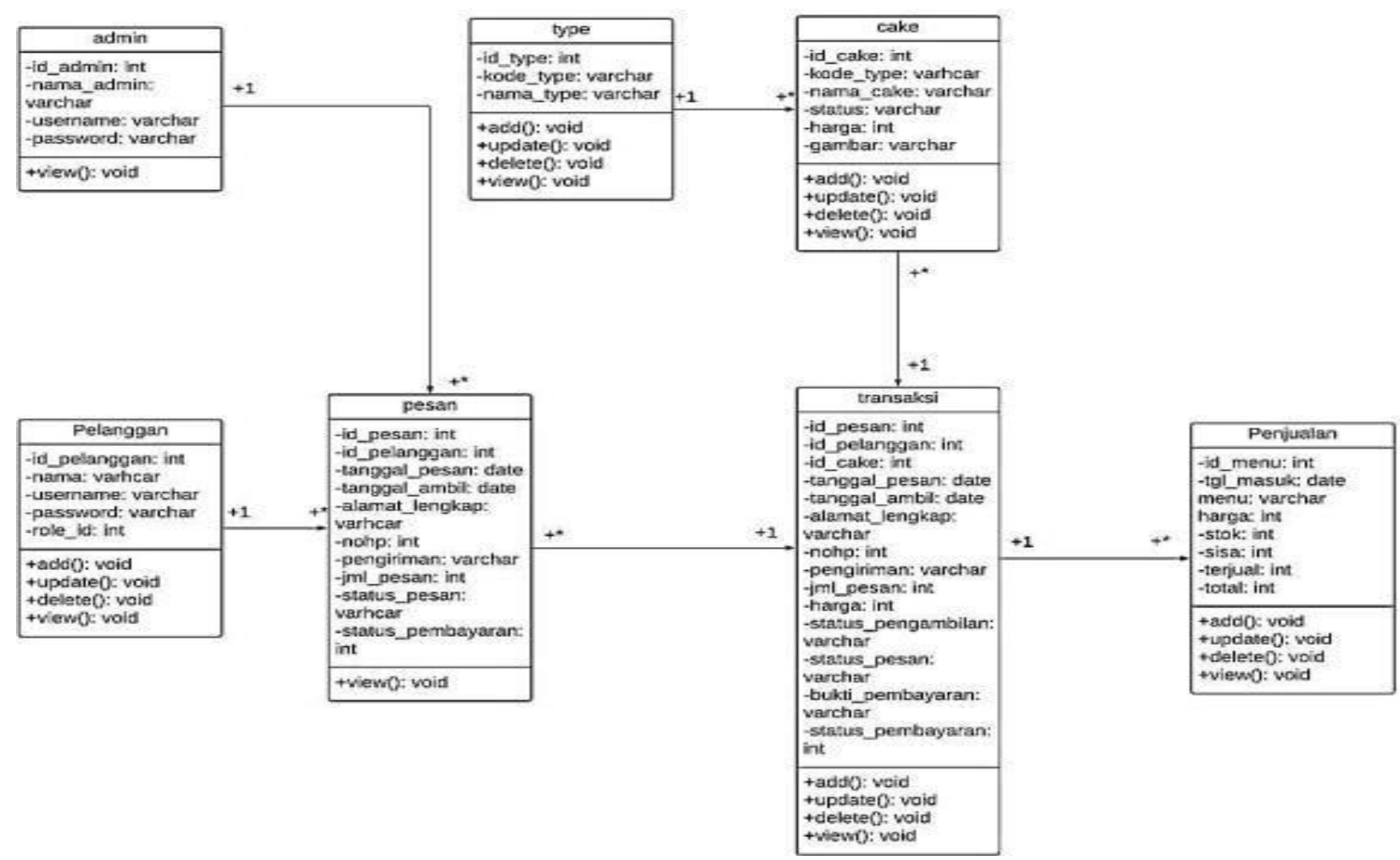

Gambar 2. Class Diagram

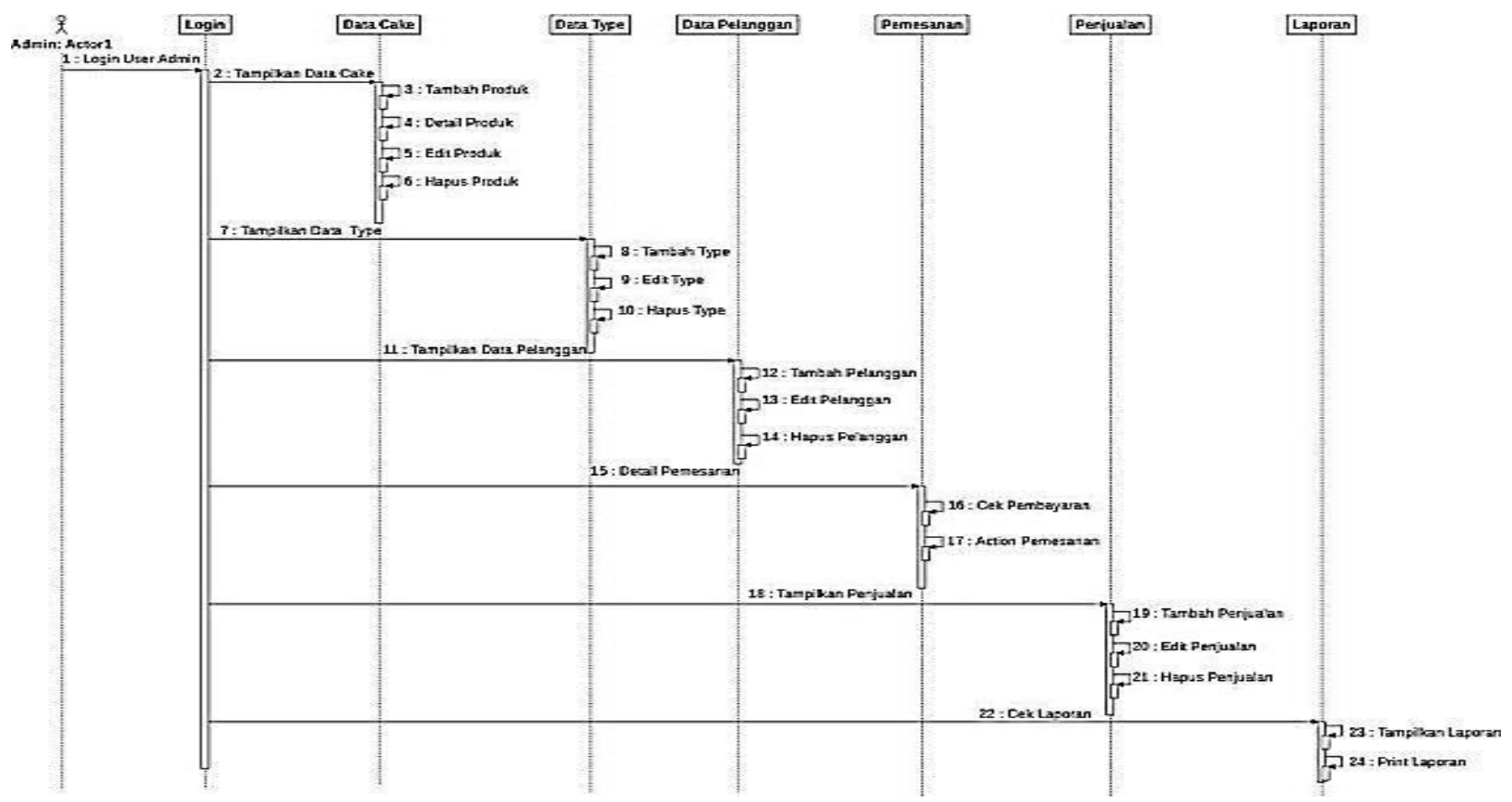

Gambar 3. Sequence Diagram

\subsection{Sequence Diagram}

Jika berhasil,admin tersebut dapat masuk ke halaman

Sequence diagram pada gambar 3, data cake, data type, data pelanggan, data menggambarkan proses aliran kerja dari login admin. Prosesnya dimulai dengan admin masuk ke pemesanan, data penjualan, laporan yaitu laporan pemesanan dan laporan penjualan. dalam form login pada aplikasi terlebih dahulu. Analisis Perancangan E-Commerce Tart \& Cake Fafa Cheese 


\subsection{Activity Diagram Login Pelanggan}

Activity diagram login pelanggan pada gambar 4, diawali dengan masuk ke situs website Toko Fafa Cheese, lalu memilih menu login dan memasukkan username serta password. Jika username dan password tidak valid, Pelanggan memasukkan username serta password kembali. Jika valid, Pelanggan diberikan hak akses masuk halaman utama agar bisa melakukan transaksi pemesanan.

\subsection{Activity Diagram Pesanan Cake}

Dapat dilihat pada gambar 5, Activity diagram pesanan cake. Pelanggan dapat melakukan pemesanan cake pada website dengan cara melakukan login, lalu sistem akan menampilkan halaman utama, pelanggan dapat memilih menu cake, sistem akan menampilkan halaman cake, selanjutnya pelanggan dapat memilih tombol detail dan sistem akan menampilkan detail produk cake, setelah itu pelanggan memilih tombol pesan, pelanggan dipersilahkan untuk mengisi form pemesanan dan klik tombol pesan sistem akan menampilkan konfirmasi pemesanan telah berhasil dan silahkan checkout.

\subsection{Activity Diagram Konfirmasi Pembayaran \\ Pelanggan}

Dapat dilihat pada gambar 6, Activity diagram konfirmasi pembayaran untuk mengonfirmasikan pembayaran yang telah dilakukan dengan cara transfer via ATM ataupun melalui Bank. Pelanggan terlebih dahulu melakukan setting tanggal ambil cake setelah itu memasukkan data transaksi dengan upload bukti pembayaran dan simpan strok nota pembayaran.

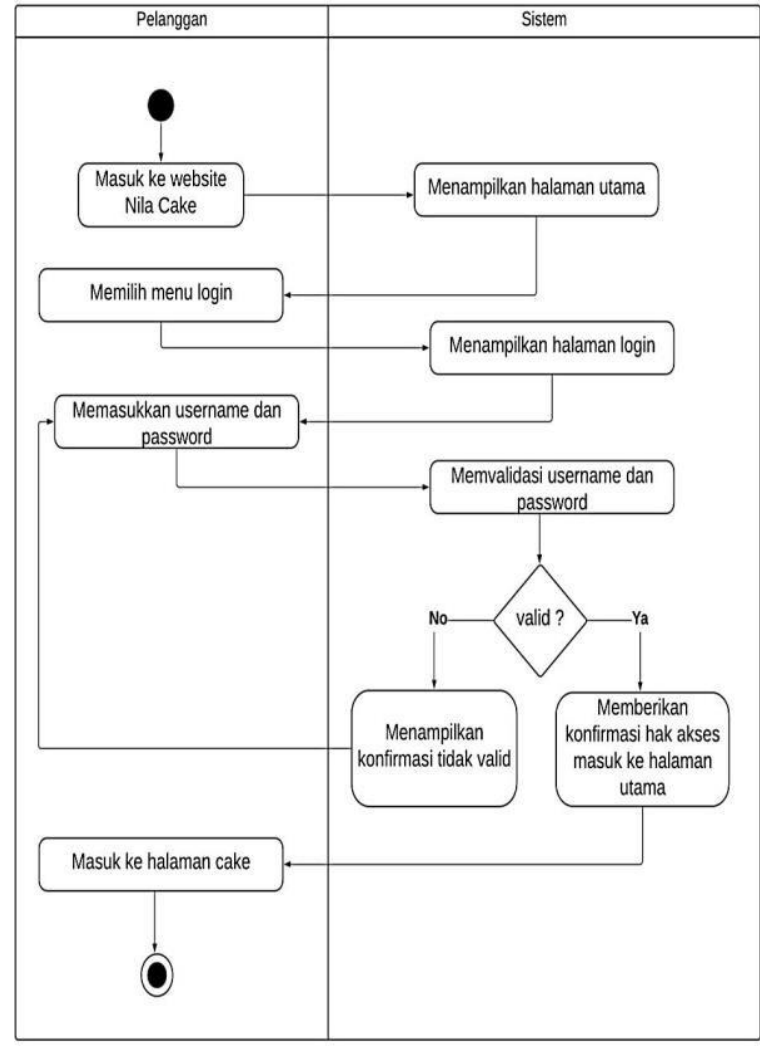

Gambar 4. Activity Diagram Login Pelanggan

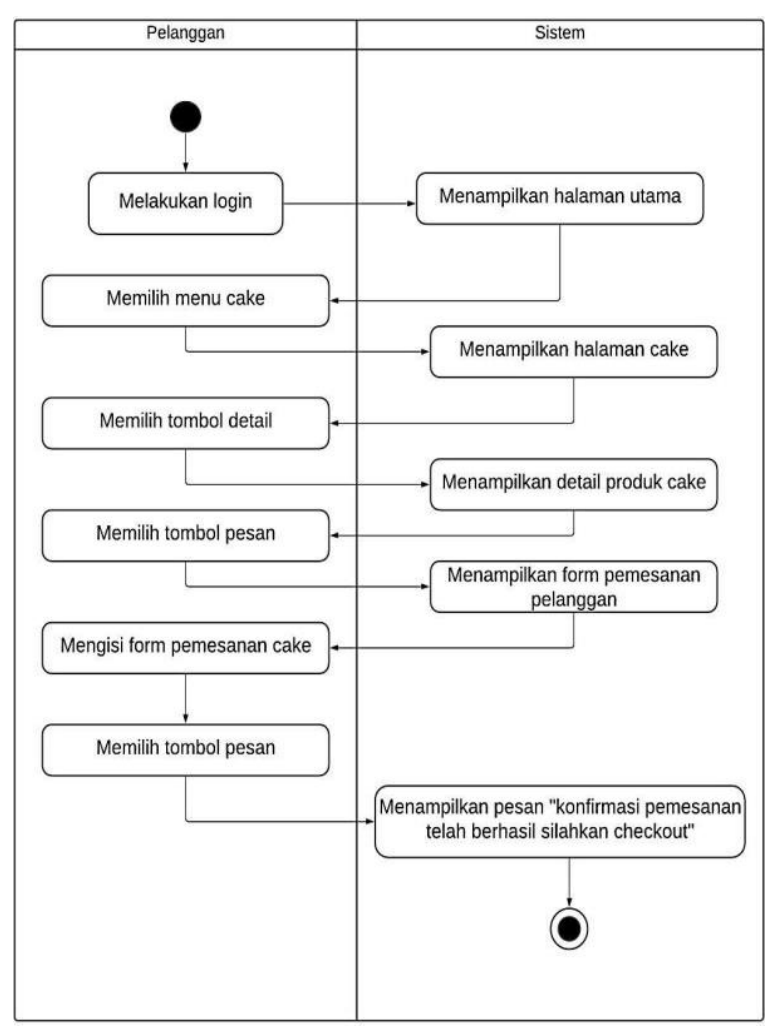

Gambar 5. Activity Diagram Pesanan Cake 


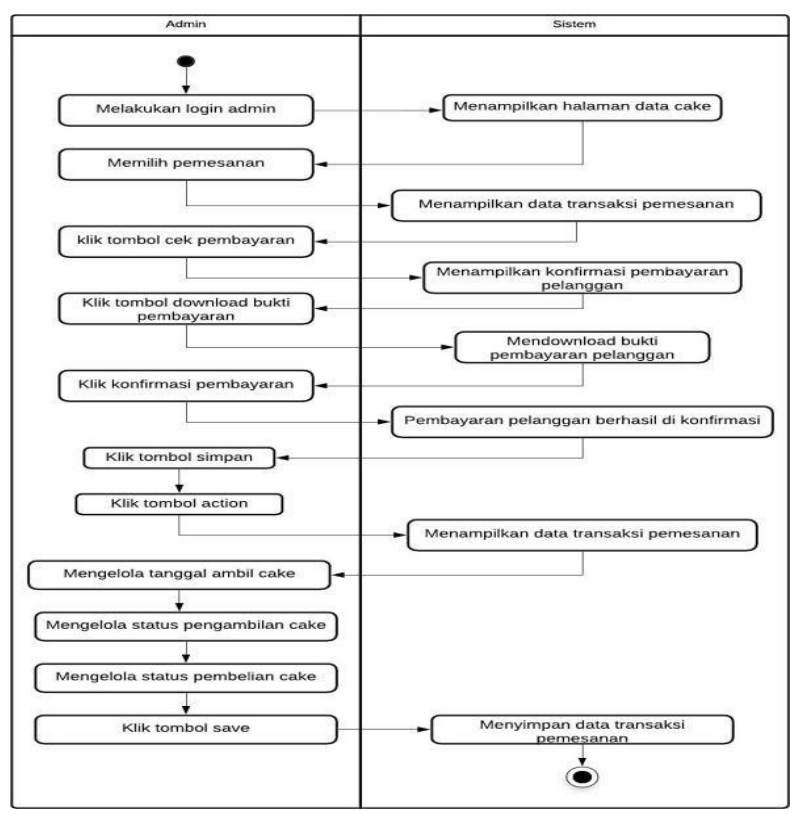

Gambar 6. Activity Diagram Konfirmasi

\section{Pembayaran Pelanggan}

\subsection{Activity Diagram Login Admin}

Activity diagram login admin ditampilkan pada gambar 7. Activity diagram login admin diawali dengan masuk ke situs website Toko Fafa Cheese, lalu memilih menu login dan memasukkan username serta password. Jika username dan password tidak valid, Pelanggan memasukkan username serta password kembali. Jika valid, Admin diberikan hak akses masuk ke Home admin.

\subsection{Activity Diagram Mengelola Data Pesanan}

\section{Cake Admin}

Activity diagram mengelola data pesanan cake admin dapat dilihat pada gambar 8. Admin dapat mengunduh bukti pembayaran pelanggan, konfirmasi pembayaran pelanggan, mengelola status pengambilan cakedan status pembelian cake.

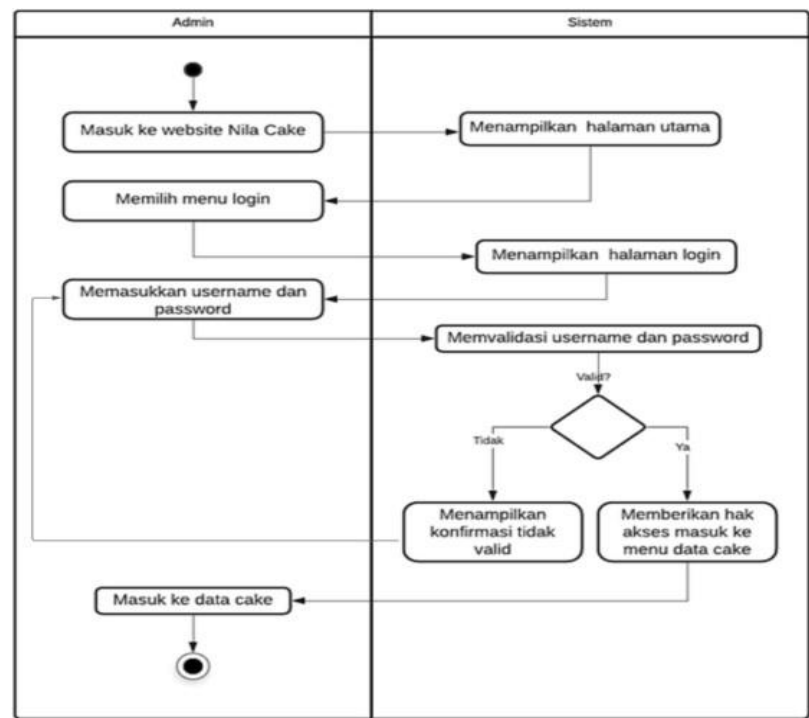

Gambar 7. Activity Diagram Login Admin

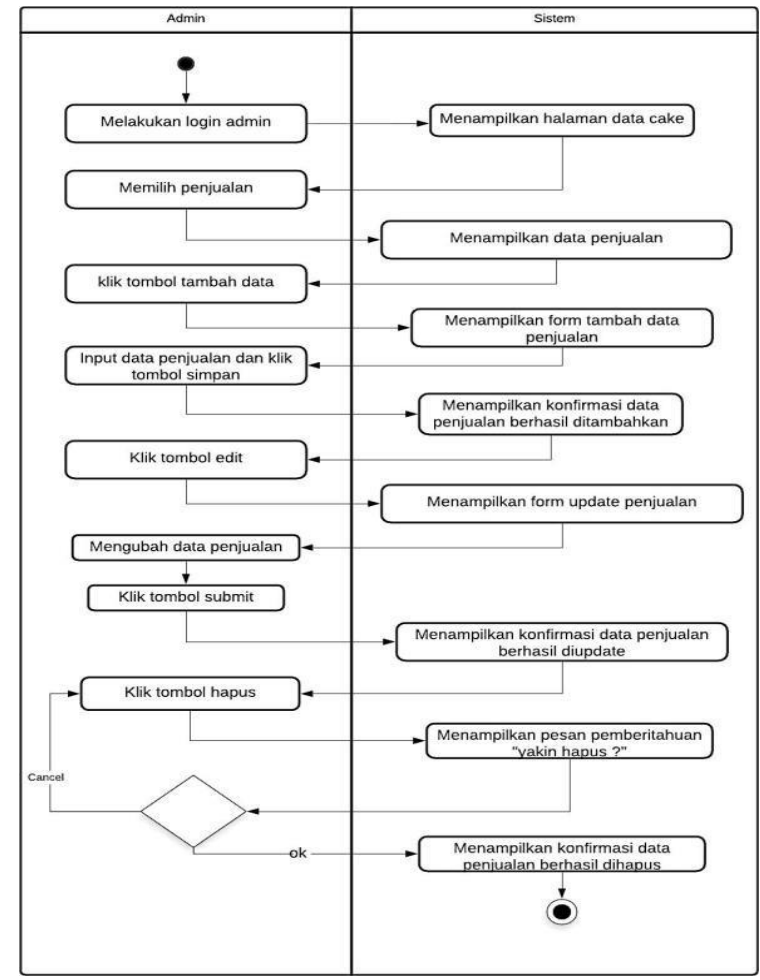

Gambar 8. Activity Diagram Mengelola Data

\section{Pesanan Cake}

\subsection{Activity Diagram Mengelola Data Penjualan} Cake

Activity diagram mengelola data penjualan cake ditampilkan pada gambar 9. Admin dapat menambahkan data penjualan cake dengan klik tombol tambah data lalu input menu cake, tanggal penjualan, harga cake, stok cake, sisa cake, jumlah 
cake yang terjual, dan total cake dan klik tombol simpan, selanjutnya sistem akan memberikan konfirmasi data penjualan berhasil ditambahkan. Admin juga dapat mengedit dan menghapus data penjualan.

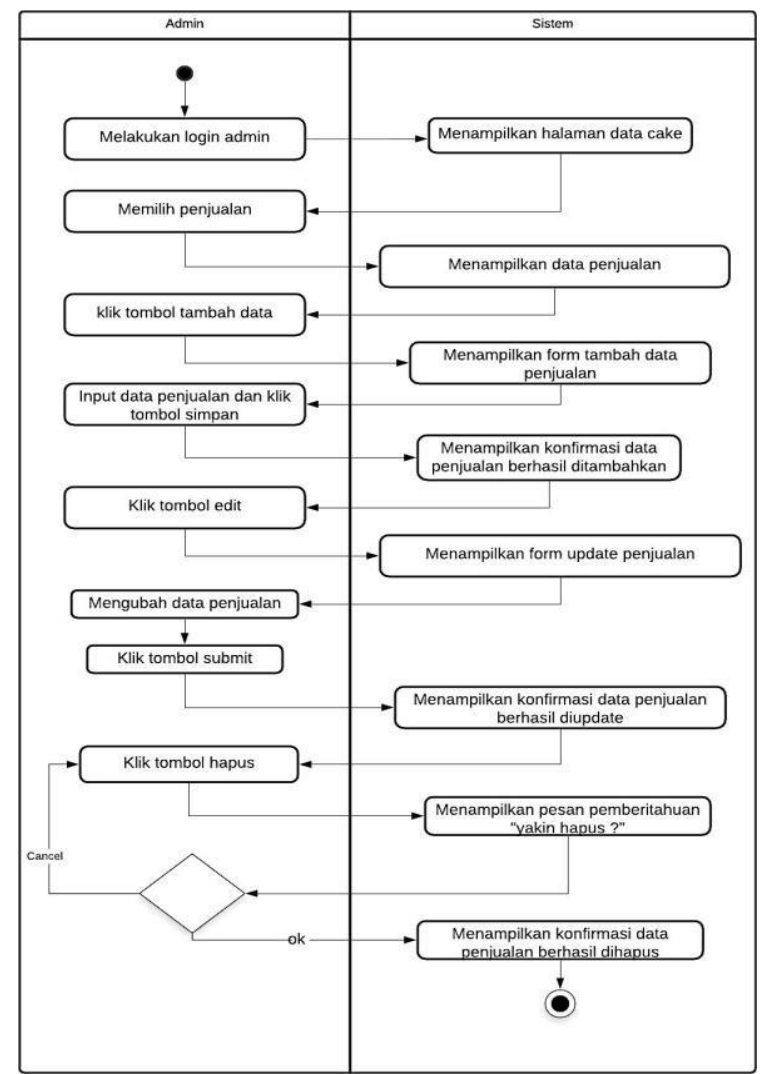

Gambar 9. Activity Diagram Mengelola Data Penjualan Cake

\subsection{Sitemap Pelanggan}

Sitemap pelanggan. Terdapat sitemap yang memperlihatkan susunan menu atau hierarki menu dari aplikasi web yang menggambarkan isi dari setiap halaman. Sitemap pada pelanggan terdiri dari halaman utama, menu cake, transaksi, register, dan login.

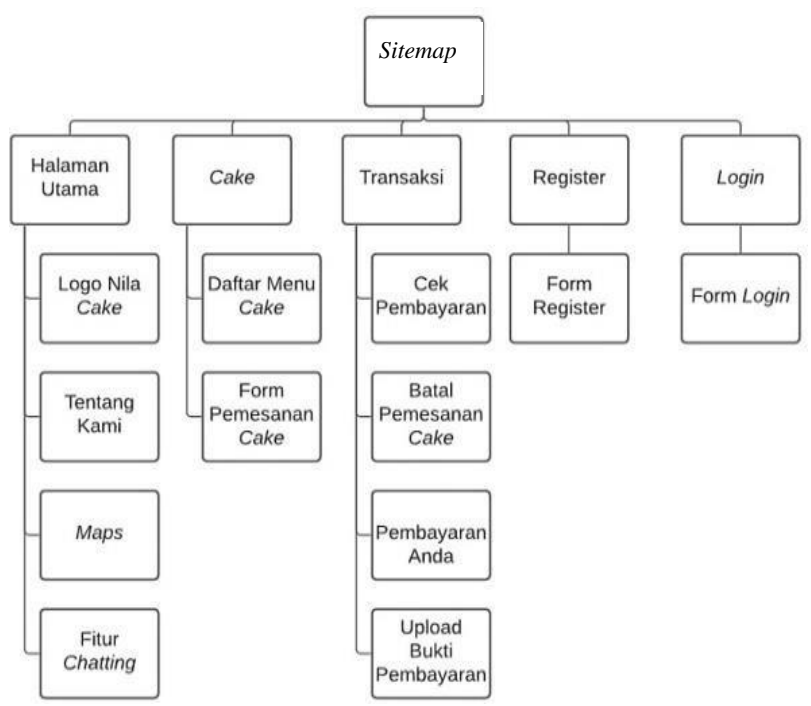

Gambar 10. Sitemap Pelanggan

\subsection{Sitemap Admin}

Sitemap admin pada gambar 11, terdiri dari data cake, data type cake, data pelanggan, data penjualan, laporan pemesanan, laporan penjualan, logout dan ganti password.

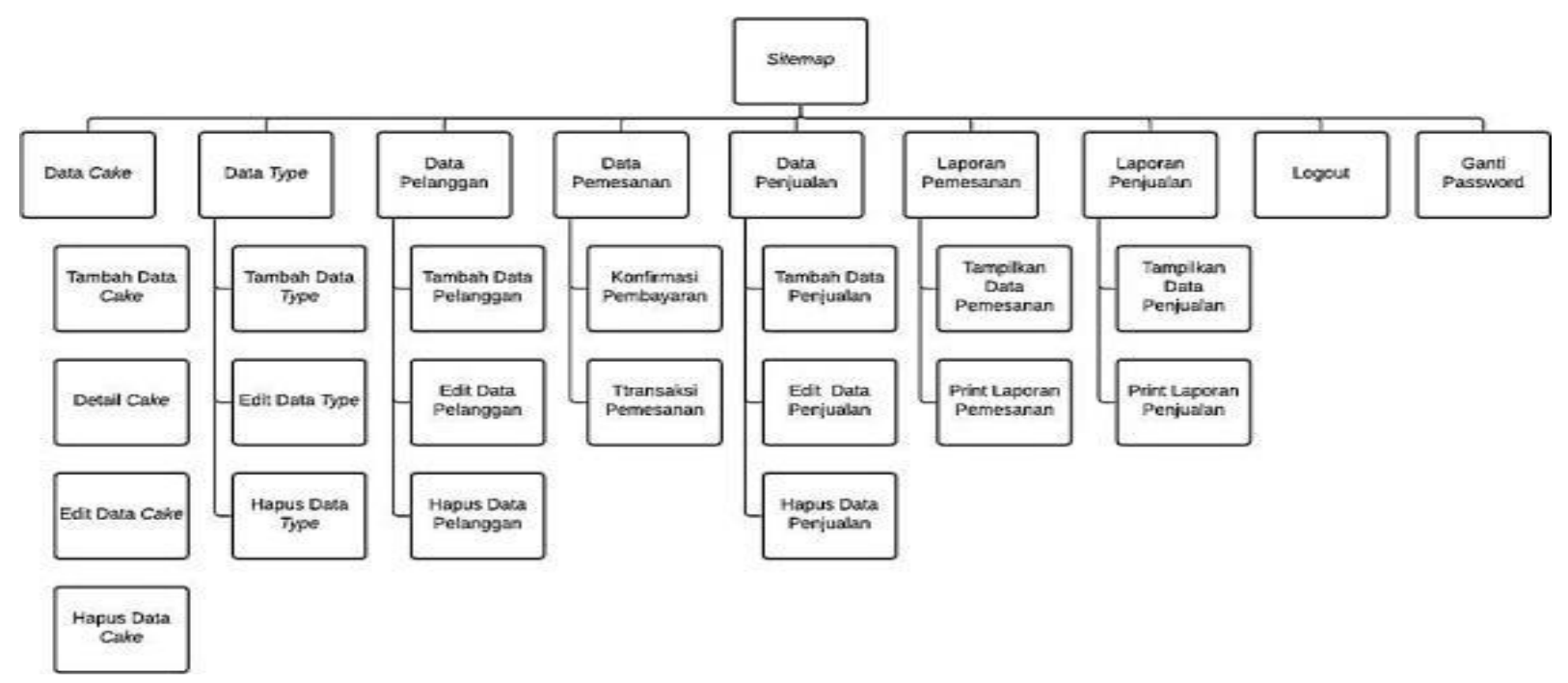

Gambar 11. Sitemap Admin 


\subsection{Struktur Basis Data (Database)}

Basis data merupakan sekumpulan informasi yang sangat berguna, yang diorganisasikan dalam suatu bentuk yang saling berhubungan. Penerapan basis data dalam aplikasi adalah suatuaplikasi yang mengintegrasikan kumpulan dari data yang saling berhubungan satu dengan yang lainnya. Sebelum pembuatan program terlebih dahulu perlu dibuat datanya. Adapun basis data yang digunakan dalam aplikasi penjualan cakesebagai berikut :

1. Desain Tabel Pelanggan

Dapat dilihat pada tabel 1, tabel pelanggan terdiri dari 5 atribut id_pelanggan nama, username, password, dan role_id. Primary key dari tabel pelanggan adalah id_pelanggan. Primary key berfungsi sebagai identitas untuk membedakan antar record dan tabel sedangkan field yang tidak dipilih sebagai primary key disebut dengan alternate key, role_id pada tabel pelanggan bermaksud apakah pelanggan yang mendaftarkan akun untuk hak akses masuk sebagai pelanggan, jika admin maka role_id 1 dan pelanggan role_id2.

Tabel 1. Desain Tabel Pelanggan

\begin{tabular}{lcccc}
\hline No & \multicolumn{2}{c}{ Nama FieldTipe } & $\begin{array}{c}\text { Panjang } \\
\text { Data }\end{array}$ & Karakter \\
\hline 1. & \multicolumn{2}{c}{ id_pelangganInteger } & 11 & Id Pelanggan \\
2. & nama & Varchar & 120 & $\begin{array}{c}\text { Nama } \\
\text { Pelanggan }\end{array}$ \\
3. & username & Varchar & 120 & $\begin{array}{l}\text { Username } \\
\text { Pelanggan }\end{array}$ \\
4. & password & Varchar & 120 & $\begin{array}{c}\text { Password } \\
\text { Pelanggan }\end{array}$ \\
\hline
\end{tabular}

\section{Desain Tabel Cake}

Tabel cake (lihat tabel 2) digunakan untuk menyimpan semua data cake yang diperlukan. Dalam tabel cake terdapat 6 atribut yaitu id_cake, kode_type, nama_cake, status, harga, gambar. Primary key dari tabel cake adalah id_cake. Primary key berfungsi sebagai identitas untuk Analisis Perancangan E-Commerce Tart \& Cake Fafa Cheese membedakan antara record dan tabel sedangkan field yang tidak dipilih sebagai primary key disebut dengan alternate key, kode_type pada tabel cake bermaksud untuk memberikan ukuran cake yang tersedia di toko Fafa Cheese dan dalam bentuk apa cake itu dijual seperti box atau cup, status pada tabel cake bermaksud untuk memberikan pelanggan agar mengetahui apakah status cake tersedia atau tidak tersedia

Tabel 2. Desain Tabel Cake

\begin{tabular}{|c|c|c|c|c|}
\hline No & $\begin{array}{c}\text { Nama } \\
\text { Field }\end{array}$ & Tipe Data & $\begin{array}{l}\text { Panjang } \\
\text { Karakter }\end{array}$ & Ket \\
\hline 1. & id_cake & Integer & 11 & Id Cake \\
\hline 2. & kode_type & Varchar & 120 & $\begin{array}{l}\text { Kode } \\
\text { Type } \\
\text { Cake }\end{array}$ \\
\hline 3. & nama_cake & Varchar & 225 & $\begin{array}{l}\text { Nama } \\
\text { Cake }\end{array}$ \\
\hline 4. & status & Varchar & 50 & $\begin{array}{l}\text { Status } \\
\text { Cake }\end{array}$ \\
\hline 5. & harga & Integer & 11 & $\begin{array}{l}\text { Harga } \\
\text { Cake }\end{array}$ \\
\hline 6. & gambar & Varchar & 255 & $\begin{array}{c}\text { Gambar } \\
\text { Cake }\end{array}$ \\
\hline
\end{tabular}

3. Desain Tabel Penjualan

Tabel penjualan pada tabel 3, digunakan untuk menyimpan semua data penjualan yang diperlukan. Tabel penjulan terdapat 8 atribut yaitu id_menu, tgl_masuk, menu, harga, stok, sisa, terjual, total. Primary key dari tabel penjualan adalah id_menu. Primary key berfungsi sebagai identitas untuk membedakan antara record dan tabel sedangkan field yang tidak dipilih sebagai primary key disebut dengan alternate key, tgl_masuk pada tabel penjualan bermaksud sebagai tanggal masuk penjualan per-tanggal, bulan dan tahun, stok bermaksud sebagai jumlah masing - masing cake yang masih tersedia di toko Fafa Cheese, sisa adalah cake yang berkurang dari stok cake, terjual adalah 
jumlah cake yang sudah dibeli pelanggan, total adalah total harga dari cake yang dibeli pelanggan.

Tabel 3. Desain Tabel Penjualan

\begin{tabular}{|c|c|c|c|c|}
\hline$\overline{N o}$ & $\begin{array}{l}\text { Nama } \\
\text { Field }\end{array}$ & $\begin{array}{l}\text { Tipe } \\
\text { Data }\end{array}$ & \multicolumn{2}{|c|}{$\begin{array}{l}\text { Panjang Keterangan } \\
\text { Karakter }\end{array}$} \\
\hline 1. & id_menu & Integer & 11 & $\begin{array}{l}\text { Id Menu } \\
\text { Cake }\end{array}$ \\
\hline 2. & tgl_masuk & Date & - & $\begin{array}{l}\text { Tgl Masuk } \\
\text { Data } \\
\text { Penjualan }\end{array}$ \\
\hline 3. & menu & Varchar & 150 & Menu Cake \\
\hline 4. & harga & Integer & 50 & Harga Cake \\
\hline 5. & stok & Integer & 50 & Stok Cake \\
\hline 6. & sisa & Integer & 50 & Sisa Cake \\
\hline 7. & terjual & Integer & 50 & $\begin{array}{l}\text { Cake } \\
\text { Terjual }\end{array}$ \\
\hline 8. & total & Integer & 50 & $\begin{array}{l}\text { Total } \\
\text { Penjualan } \\
\text { Cake }\end{array}$ \\
\hline
\end{tabular}

\section{Desain Tabel Transaksi}

Tabel transaksi ditampilkan pada tabel 4, digunakan untuk menyimpan semua data transaksi yang diperlukan. Tabel transaksi terdapat 14 atribut, id_pesan, id_pelanggan, id_cake, tanggal_pesan, tanggal_ambil, alamat_lengkap, nohp, pengiriman, jml_pesan, harga, status_pesan, bukti_pembayara, status_pembayaran Primary key dari tabel transaksi adalah id_pesan. status_pengambilan pada tabel transaksi bermaksud sebagai cake sudah diambil atau belum diambil, status_pesan pada tabel pesan bermaksud untuk memberikan status pemesanan pelanggan sudah selesai atau belum selesai, status_pembayaran pada tabel pesan bermaksud untuk memberikan status pembayaran pelanggan sudah lunas atau belum lunas.
Tabel 4. Desain Tabel Transaksi

\begin{tabular}{|c|c|c|c|c|}
\hline No & Nama Field & $\begin{array}{l}\text { Tipe } \\
\text { Data }\end{array}$ & $\begin{array}{l}\text { Panjang } \\
\text { Karakter }\end{array}$ & Ket. \\
\hline 1. & $\begin{array}{c}\text { Id_- } \\
\text { pesan }\end{array}$ & Integer & 11 & $\begin{array}{l}\text { Id Pesanan } \\
\text { Pelanggan }\end{array}$ \\
\hline 2. & id_pelanggan & Integer & 11 & Id Pelanggan \\
\hline 3. & id_cake & Integer & 11 & Id cake \\
\hline 4. & tanggal_pesan & Date & - & $\begin{array}{l}\text { Tanggal } \\
\text { Pesan Cake }\end{array}$ \\
\hline 5. & tanggal_ambil & Date & - & $\begin{array}{l}\text { Tanggal } \\
\text { Ambil Cake }\end{array}$ \\
\hline 6. & $\begin{array}{l}\text { alamat_- } \\
\text { lengkap }\end{array}$ & Varchar & 225 & $\begin{array}{l}\text { Alamat } \\
\text { Lengkap }\end{array}$ \\
\hline 8. & pengiriman & Varchar & 150 & $\begin{array}{l}\text { Pengiriman } \\
\text { Cake Dengan } \\
\text { ViaGrab atau } \\
\text { ambil di Toko }\end{array}$ \\
\hline 9. & jml_pesan & Integer & 11 & $\begin{array}{l}\text { Jumlah } \\
\text { Pesan Cake }\end{array}$ \\
\hline 10 & harga & Integer & 120 & Harga Cake \\
\hline 11. & $\begin{array}{c}\text { status__ } \\
\text { pengambilan }\end{array}$ & Varchar & 50 & $\begin{array}{l}\text { Status Peng- } \\
\text { ambilan Cake }\end{array}$ \\
\hline 12. & status_pesan & Varchar & 50 & $\begin{array}{l}\text { Status } \\
\text { Pesan Cake }\end{array}$ \\
\hline 13. & $\begin{array}{c}\text { bukti__ } \\
\text { pembayaran }\end{array}$ & Varchar & 120 & $\begin{array}{l}\text { Bukti } \\
\text { Pembayaran } \\
\text { pelanggan }\end{array}$ \\
\hline 14. & $\begin{array}{c}\text { status_ } \\
\text { pembayaran }\end{array}$ & Integer & 11 & $\begin{array}{l}\text { Status } \\
\text { Pembayaran } \\
\text { pelanggan }\end{array}$ \\
\hline
\end{tabular}

\subsection{Desain antarmuka}

Rancangan akhir adalah perancangan antarmuka (user interface), antarmuka pengguna merupakan bentuk tampilan grafis yang berhubungan langsung dengan pengguna. Berikut dijabarkan antarmuka yang dirancang .

1. Halaman Form Login

2. Halaman Registrasi

3. Tampilan Fitur Chatting Pelanggan

4. Halaman Menu Cake Pelanggan

5. Form Pemesanan Cake Pelanggan.

6. Form Transaksi Pembayaran Pelanggan

7. Halaman Data Cake Admin 
8. Halaman Data Transaksi Pemesanan Pelanggan

9. Halaman Data Penjualan Cake

10. Halaman Laporan Pemesanan Cake

11. Halaman Laporan Penjualan Cake

Selain merancang antarmuka, perancangan juga dilakukan pada Nota pembayaran pelanggan. Terdapat nama toko Fafa Cheese, alamat toko Fafa Cheese, nomor hp toko Fafa Cheese, tanggal pemesanan cake, nama pelanggan, menu cake, tanggal ambil cake, alamat cake nomor hp pelanggan, pengiriman cake, status pembayaran cake, jumlah pesanan cake, harga cake, total pembayaran cake. Desain Nota dapat dilihat pada gambar 12 .

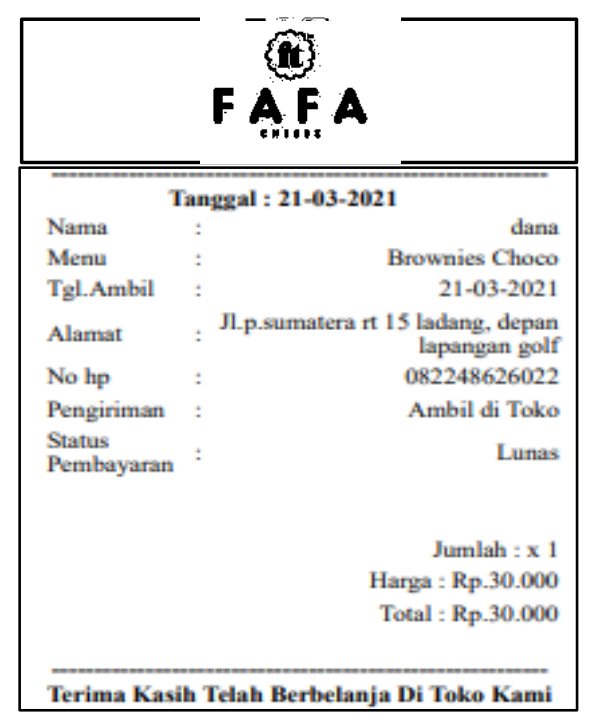

\section{Gambar 12. Desain Nota Pembayaran}

\section{Pelanggan}

Terakhir adalah rancangan tampilan laporan data penjualan cake (lihat tabel 5). Laporan data penjualan cake ini dapat dicetak atau diserahkan langsung kepada pemilik Toko Fafa Cheese.
Tabel 5. Tampilan Laporan Data Penjualan Cake

\begin{tabular}{|c|c|c|c|c|c|c|}
\hline Id & Menu & Stok & $\begin{array}{l}\text { Si- } \\
\text { sa }\end{array}$ & $\begin{array}{l}\text { Ter- } \\
\text { jual }\end{array}$ & Harga & Total \\
\hline 1 & $\begin{array}{l}\text { Vanilla } \\
\text { Cheese } \\
\text { Brownies }\end{array}$ & 17 & 10 & 7 & 30.000 & 210.000 \\
\hline 2 & $\begin{array}{l}\text { Cheese } \\
\text { Brownies }\end{array}$ & 7 & 4 & 3 & 30.000 & 90.000 \\
\hline 3 & $\begin{array}{l}\text { Choco } \\
\text { Puding }\end{array}$ & 10 & 3 & 7 & 30.000 & 210.000 \\
\hline 4 & $\begin{array}{l}\text { Coklat } \\
\text { Cake }\end{array}$ & 9 & 7 & 2 & 20.000 & 40.000 \\
\hline 5 & $\begin{array}{l}\text { Bhantu } \\
\text { Milkbath }\end{array}$ & 6 & 5 & 1 & 25.000 & 25.000 \\
\hline 6 & $\begin{array}{l}\text { Red } \\
\text { Velvet } \\
\text { Klapertart }\end{array}$ & 2 & 0 & 0 & 25.000 & 0 \\
\hline 7 & Buko & 10 & 9 & 1 & 25.000 & 25.000 \\
\hline 8 & $\begin{array}{l}\text { Pandan } \\
\text { Regal }\end{array}$ & 8 & 7 & 1 & 25.000 & 25.000 \\
\hline 9 & Cheese & 9 & 6 & 3 & 35.000 & 105.000 \\
\hline 10 & $\begin{array}{l}\text { Fudgy } \\
\text { Brownies } \\
\text { Potong } 20 \\
\text { Vanila }\end{array}$ & 4 & 3 & 1 & 110.000 & 110.000 \\
\hline 11 & $\begin{array}{l}\text { Cheese } 18 \\
\text { Brownies }\end{array}$ & 4 & 1 & 3 & 180.000 & 540.000 \\
\hline 12 & $\begin{array}{l}\text { Cheese } \\
\text { Brownies }\end{array}$ & 4 & 3 & 1 & 180.000 & 180.000 \\
\hline 13 & $\begin{array}{l}\text { Choco } \\
\text { Brownies }\end{array}$ & 6 & 5 & 1 & 180.000 & 180.000 \\
\hline 14 & Hias & 3 & 2 & 1 & 165.000 & 165.000 \\
\hline 15 & $\begin{array}{l}\text { Brownies } \\
\text { Lapis } \\
\text { Puding }\end{array}$ & 9 & 5 & 4 & 175.000 & 700.000 \\
\hline \multicolumn{6}{|c|}{ TOTAL } & 2.605 .000 \\
\hline
\end{tabular}

\section{KESIMPULAN}

Pembangunan aplikasi penjualan tart dan cake pada toko Fafa Cheese menggunakan metode pengembangan sistem waterfall tetapi tidak sampai ke tahapan implementasi dan pengujian. Dalam penelitian selanjutnya, pembuatan aplikasi penjualan cake pada toko Fafa Cheese dapat dilakukan dengan berbasis website, agar e-commerce dapat berjalan secara online. 


\section{DAFTAR PUSTAKA}

[1] Kirana, D. 100 Kreasi Cake Ulang Tahun Anak. (n.p.): Gramedia Pustaka Utama. 2013.

[2] Setiawan, B., Suliawati, S., \& Arfah, M, "Menentukan Kriteria Yang Paling Berpengaruh Antara Investasi, Produk, Potensi Keuntungan Dan Merek Terhadap Keputusan Wirausahawan Membeli Franchise (Studi Kasus Franchise Fafa Cheese)," Buletin Utama Teknik, 16(3), 219223., 2021.

[3] Susilawati, A., "Pengaruh Produk Terhadap Tingkat Kepuasan Pelanggan di Fafa Cheese Yogyakarta (Skripsi, STP AMPTA Yogyakarta). 2018.

[4] Bairizki, A., "Pengaruh Harga, Promosi dan Kualitas Produk Terhadap Keputusan Pembelian Dalam Meningkatkan Penjualan (Studi Kasus Pada Ud Ratna Cake \& Cookies)," VALID Jurnal Ilmiah, 14(2), 7182. 2017.

[5] Gunawan, D., Hastuti, D. P., \& Andriani, R., "Sistem Informasi Penjualan Berbasis Web Pada Restoran Caki Cake Karawang," Jurnal Akrab Juara, 3(1), 1-16. 2018.

[6] Fatonah, A., Ningsih, R., \& Aprilliah, W., "Perancangan Sistem Informasi Penjualan Kue Berbasis Web Pada Toko Ana Cake Cikarang," Jurnal Sistem Informasi, 4(2), 273-280. 2015.

[7] Istanti, L. N., Agustina, Y., Wijijayanti, T., \& Dharma, B. A., "Pentingnya Penyusunan Laporan Keuangan Umkm Bagi Para Pengusaha Bakery, Cake And Pastry (Bcp) Di Kota Blitar," Jurnal Graha Pengabdian, 2(2), 163-171. 2020.

[8] Naufal, M. M. A., Hernawati, E., \& Qana'a, M., "Aplikasi Penjualan Kue Berbasis Web Pada Toko Yanie's Cakes And Cookies," eProceedings of Applied Science, 5(1). 2019.

[9] Wibowo, T. J., Suryasari, S., \& Aribowo, A., "Sistem Informasi Penunjang Proses Pemesanan dan Desain Kue Pada Toko Kue Artisan Online Berbasis Web," Ultima InfoSys: Jurnal Ilmu Sistem Informasi, 10(1), 48-54. 2019.

[10] I. Sommerville, Software Engineering. Netherlands, Pearson, 2015.

[11] F. H. Utami dan Asnawati. Rekayasa Perangkat Lunak. Deepublish. 2015 